\title{
Would you like to know what is wrong with you? On telling the truth to patients with dementia
}

Marek Marzanski Worcestershire Community Healthcare NHS Trust

\begin{abstract}
Objectives-To discover what dementia sufferers feel is wrong with them; what they have been told and by whom, and what they wish to know about their illness.

Background-Ethical guidelines regarding telling truth appear to be equivocal. Declarations of cognitively intact subjects, attitudes of family members and current psychiatric practice all vary, but no previous research has been published concerning what patients with dementia would in fact like to know about their diagnosis and prognosis. Design-Questionnaire study of the patients' opinions.

Setting-Old Age Psychiatry Service in Worcester. Participants-30 consecutive patients with dementia.

Results-The quality of information received has been poor and many patients have no opportunity to discuss their illness with anybody. Despite that almost half of the participants in this study had adequate insight and a majority declared that they would like to know more about their predicament.

Conclusions-Although many patients would like to know the truth, the rights of those who do not want to know should also be respected. Therefore the diagnosis of dementia should not be routinely disclosed but (just as in other disorders) health care professionals should seek to understand their patients' preferences and act appropriately according to their choice.

(Fournal of Medical Ethics 2000;26:108-113)
\end{abstract}

Keywords: Dementia; telling truth; patients' perspectives

\section{Introduction}

Dementia is a syndrome, usually of a chronic and progressive nature, in which there is decline of cognitive functions, accompanied by deterioration in emotional control, language skills and social behaviour. It occurs in Alzheimer's disease, cerebravascular disorders and other conditions primarily or secondarily affecting the brain. Although dementia may begin at any age most frequently it affects the elderly. In the majority of cases, its course is irreversible-despite significant progress no effective treatment is currently available. Trying to help people with dementia is not only a challenge to physicians' professional skills but also confronts us with difficult questions about the limits of individual autonomy and medical paternalism, the dignity of persons and their best interests. Here I shall address an apparently simple problem concerning the giving of diagnostic information to people with dementia. A recent survey of old age psychiatry consultants showed that a majority of them "rarely" or only "sometimes" informed their patients about the diagnosis and almost never about the prognosis. Providing information seemed to depend on the level of impairment. Thirty-eight per cent of consultants "nearly always" informed mildly demented patients, but in the case of moderate and severe dementia only $13 \%$ and $6 \%$ respectively discussed the diagnosis with their patients. However, $98 \%$ of the respondents "nearly always" informed patients' families and carers about the diagnosis and prognosis. ${ }^{1}$ Similar practice has been observed among geriatricians, although in cases of mild dementia they tend to tell patients more and their carers less than psychiatrists do. ${ }^{2}$

The majority of dementia sufferers' relatives (57-83\%) do not want the patient to be told his or her diagnosis, but more than $70 \%$ of the relatives would want to be told the truth if they had the disorder themselves. ${ }^{3}$ However, where the diagnosis had been given, the majority of the carers found it helpful both for themselves $(98 \%)$ and for the patients $(84 \%) .{ }^{5}$ Only one study attempted to elicit patients' preferences. When attendees at two primary care practices were presented with a vignette of a patient with Alzheimer's disease an overwhelming majority (92\%) declared they would like to know the truth. Almost the same proportion $(87 \%)$ stated that members of their families or friends should have been fully informed. However, the participants in this study were cognitively intact and almost half of them were under the age of $50 .{ }^{6} \mathrm{I}$ am not aware of any published study exploring the wishes and preferences of patients 
with dementia and therefore I have decided to undertake this inquiry.

\section{What do the patients with dementia want to know?}

The aim of my study was to explore what the patients think is wrong with them, whether and what they have been told by their doctors and what they would like to know about their illness.

Thirty consecutive patients seen by the author between October and December 1997 in the Old Age Psychiatry Service in Worcester participated in the study. There were 20 women and 10 men. Their ages ranged from 63 to 92 years (average $=$ 81). At the time of examination, 11 participants were inpatients, 19 were outpatients. They had been in contact with the psychiatric service from one day to 17 years (average $=1$ year and 10 months). All of them had a clinical diagnosis of dementia based on ICD-10 criteria $^{7}$ including Alzheimer's disease (11), vascular dementia (9) and other/unspecified dementias (10). In addition consensus guidelines were used to make a diagnosis of dementia with Lewy bodies in one of the otherwise unspecified dementias. ${ }^{8}$ Participants' cognitive states were assessed using the MiniMental State examination (MMSE $)^{9}$; scores ranged from 7 to 29 (median $=18$, average $=18$ ). All participants gave verbal consent and answered a set of standard questions regarding the information they had received about their illness (the questionnaire is available from the author on request). The answers were recorded verbatim and will be the subject of further analysis.

\section{INSIGHT: 'WHAT DO YOU THINK IS WRONG WITH} YOU?'

I have assumed that the participants had adequate insight if they were able to give the correct diagnosis or, at least, to describe adequately their main symptoms. Fourteen out of 30 participants $(47 \%)$ fulfilled these criteria. The majority complained of problems with memory. No participant used the word "dementia", but a few were able to give an accurate description of their conditions. Examples are shown in table 1.

The rest of the participants (16/30) either denied any problems or gave implausible explanations of their predicaments, such as:"loneli-

Table 1

"I had a stroke, I am not very bright after that and I cannot do things as I used to" (Vascular dementia, MMSE 15).

"I do not really know what is wrong with me but I have problem with my memory and hallucinations" (Dementia with Lewy bodies, MMSE 12).

"I am not very clear in my understanding" (Alzheimer's disease, MMSE 7). ness", "old age", “stomach upset" etc. A few (4) simply stated "don't know" without further elaboration.

'WHAT HAVE YOU BEEN TOLD ABOUT YOUR ILLNESS?'

Twenty out of 30 participants reported that nobody had ever talked with them about their illness. Only in five cases had they had an opportunity to discuss it with their doctors. Sometimes the information was provided by nurses (three cases) and friends (two cases) but never by the family members. Only one participant stated that she had been told her diagnosis. In two cases, the professionals attempted to reassure the patients ("there is not much wrong with you") and advised them to take prescribed medication. Three participants reported clearly untrue explanations allegedly given by their doctors: hearing impairment, angina pectoris and bereavement had been suggested as responsible for their present conditions. Two participants declared that the content of the information they were given was rather insulting ("She told me I was mad", "She said I was completely out of my balls and very needful"). Two either did not remember or could not understand what the informers had been trying to tell them.

\section{'WHAT WOULD YOU LIKE TO KNOW?'}

The majority of the participants with dementia (21/30) declared they would like to know what was wrong with them or wished to get more information if they already knew. Ten wanted to know their diagnoses; five were interested in the possibility of improvement; and one wished to know more about the causes of the disorder. Sometimes they could not specify what exactly they would like to know (four cases), but some of their questions might have been very difficult to answer, for example: "Why me?", "How long will I suffer?"

Where the participants specified whom they would wish to give them information about their illnesses, the majority (8/12) preferred that it should be the doctor. Only rarely did patients feel that they should receive the information from other persons such as family members (two cases) or anybody with adequate knowledge (two cases).

THOSE WHO DON'T WANT TO KNOW

There were nine participants $(30 \%)$ who did not want to know what was wrong with them or to receive any information about their illness. Although we had not asked them "why", some of the patients spontaneously tried to explain their choice. Their motives seem to display a wide spectrum from probably full insight, through 
Table 2

"I already know what it is" (Vascular dementia, MMSE 15).

"I know I can't remember things but I don't think anything is wrong about that." (Alzheimer's disease, MMSE 16).

"There is no point in talking unless you can improve it - but you can't, can you?" (Alzheimer's disease, MMSE 23).

"I have enough troubles" (Vascular dementia, MMSE 28)

"I don't really want to know what is wrong with me" (Alzheimer's disease , MMSE 18).

"I would like to know if I was ill, but I am not" (Unspecified dementia, MMSE 24).

more or less conscious decisions not to know the truth, to complete denial of the illness. See table 2.

I could not find any clinical or demographic characteristics indicating those who would prefer to be told from those who would not.

\section{Discussion: dementia and the problem of truth-telling}

Methodological limitations of the study may reduce the credibility of its results. The study has been based only on the declarations of patients, without any attempt to verify them by their therapists or to compare them with the information given to carers. The subjects were cognitively impaired and might not have been able to recall what they had been told because of the memory deficits. In the milder cases, the cognitive decline may be seriously threatening for many patients. To cope with the anxiety and to maintain their self-esteem they might use various psychological defence mechanisms, such as denial and minimalisation of the impairments, avoidance in discussing the problem, or vagueness and circumstantiality when forced to do so. ${ }^{10}$ Such defence mechanisms may render their statements less accurate, as has frequently been observed in other disorders too-even in many terminally ill patients who have been told their true diagnosis but simply deny they have been told. ${ }^{11}$ However, almost half of the participants with dementia had satisfactory insight and $70 \%$ clearly declared they would like to know more about their illness. When in a parallel enquiry their statements were compared with those of cognitively intact peers with functional (predominantly depressive) disorders, no significant differences were found in the quality of received information, level of insight or the proportion of those willing to know about the illness (D Battin and M Marzanski, in preparation). Of course, this is a small study from only one old age psychiatry service, so results of similar studies elsewhere might be different. However, the self-reported reluctance of physicians from other centres to disclose information about diagnosis to dementia sufferers strongly suggests the pattern in Worcester is not unique.
ETHICAL CODES AND TELLING THE DIAGNOSIS

Moreover in the codes of medical ethics the guidelines regarding disclosure of diagnosis are not unequivocal and may be interpreted in various ways. In the Hippocratic Oath nothing about telling truth is explicitly stated. Nevertheless, even here there is a conflict between difficult-toreconcile demands. Doctors should practise their art with purity and holiness, which may imply veracity, but on the other hand, they should follow only that system or regime which they consider beneficial to their patients and they should abstain from anything that is deleterious and mischievous. Of course, the truth about dementia may be deleterious, mischievous and devastating. A modern restatement of the Hippocratic Oath, known as the Declaration of Geneva (1947), seems to ignore the problem of veracity, stating simply that the health of the patient should be the doctor's first consideration. The International Code of Medical Ethics (1968/1983) demands that a physician deal honestly with patients and colleagues, but this is really in connection with competence and professional misconduct, rather than relating to telling patients what is wrong with them. In the Declaration of Lisbon (1981), the World Medical Association stated that: "The patient has the right to accept or refuse treatment after receiving adequate information". ${ }^{12}$ This may suggest that telling the truth about diagnosis is a mere prerequisite to the choice of treatment. This impression seems to be reinforced in the ethical guidelines for the psychiatric profession. The World Psychiatric Association's Declaration of Hawaii (1977/1983) says:

"The psychiatrist should inform the patient of the nature of the condition, therapeutic procedures, including possible alternatives, and of the possible outcome. This information must be offered in a considerate way and the patient must be given the opportunity to choose between appropriate and available methods". ${ }^{13}$

But does this mean that psychiatrists have the duty to provide the information when there is no treatment? And how truthful should be the "considerate way"? Does it imply the whole truth? As much as the patient wants? As much as his physician believes is sufficient? The General Medical Council (1995) recommends that doctors, to establish and maintain trust in their relationships with patients, must give them "the information they ask for or need about their condition, its treatment and prognosis . . in a way they can understand". ${ }^{14}$ In practice, patients with dementia rarely ask for the information and many doctors seem to believe that 
because there is no cure to offer, such knowledge may be only detrimental and therefore not needed in therapeutic relationships. But can the relationships be successful without telling the truth?

ETHICAL THEORIES AND TELLING THE DIAGNOSIS

Two schools of ethical thought address these dilemmas. Deontology assumes that lying and deception are wrong in themselves and that clinicians, like everyone else, have a moral duty to tell the truth. Competent patients have a right to know their diagnosis, this information belongs to them and they should be told the truth regardless of the consequences. Consequentialism insists that the decision to tell or not to tell depends on the details of the clinical situation, and the physician should decide which course of action might be least harmful and produce the best results for the patient.

In the deontological approach the word "competent" may cause reservations - it is difficult to understand why any illness might deprive the sufferer of the right to know about it. Competence is usually defined with respect to a particular task or performance and the only relevant skill here is that of being able to "take in" the diagnostic information. At the moment the most prominent advocates of truth-telling seem to believe that the nature and degree of the disease may limit the right to information. Pitt ${ }^{15}$ claims that:

"although there is probably no point in telling those whose Alzheimer's disease is so advanced that they cannot understand their diagnosis, in all other cases the right of those who have presented as patients, to know what is thought to be wrong with them should be respected".

But it remains controversial when, if ever, a person loses that right and whether incompetence (defined by others as inability to understand diagnostic information) is enough.

Regarding the consequentialist view one might argue that in doctor-patient relationships probably nothing is more difficult to predict than the outcome of our own predictions. Not uncommonly doctors tend to attribute their own fears and hopes to the patients - surprisingly often the patients do not meet those expectations. In 1953, $90 \%$ of physicians did not inform their patients about the diagnosis of cancer. ${ }^{16}$ One of the early arguments for disclosure was the availability of radiation and chemotherapy, which could alter the course of the disease. The need for the patient's consent to initiate such treatment outweighed previous concerns about possible harm associated with breaking the bad news. Only subsequently has it been proved that most patients wanted to know their diagnosis and its consequences, and now $97 \%$ of physicians tell their patients about the nature of the disease. ${ }^{17}$ Perhaps a similar change of attitudes will occur in old age psychiatry after the introduction of the new "anti-dementia" drugs and recently a few appeals in this direction have already been launched. ${ }^{18}{ }^{19}$ Today, the attitudes and practice of old age psychiatrists remain different from the attitudes and practice of their colleagues from other specialties. Even in cases of schizophrenia and affective disorders psychiatrists tend to inform their patients much more frequently (58\% and $90 \%$ respectively). ${ }^{20}$

ARGUMENTS IN FAVOUR OF TRUTH-TELLING According to Beauchamp and Childress ${ }^{21}$ the main arguments obligating veracity are the following.

\section{Respect for autonomy}

Lies and deceit breach the autonomy of a person. ${ }^{22}$ Patients cannot make valid decisions unless they are fully informed. That usually involves informed consent to treatment but of course there are other decisions to make regarding legal aid, driving, finances and planning for the future. The argument seems not so obvious in the case of patients with profound dementia who are no longer competent free agents and whose selfgovernance may be seriously limited. Agich ${ }^{23}$ has argued that the liberal concept of autonomy which stresses independence and freedom from interference from others is neither appropriate nor suitable here. Respect for the autonomy of dementia sufferers entails a commitment to identify and establish the conditions necessary to continue their lives in the way they are still able to, and as closely as possible to the way they have normally lived. Such a commitment should involve hope, resulting in Agich's view, from meaningful relations with others. Could delivery of the devastating truth serve them better than not telling the truth?

\section{Need for trust in doctor/patient relationship}

Mutual trust cannot be built on deception and lies. In addition, concealment, even with good intentions, once started, probably would have to be continued. Its escalation might easily lead to abuse and harm of those not fit enough to be informed by those who can manipulate them according to their own needs and beliefs. On the other hand, therapeutic relationships in severe dementia may be difficult or impossible to establish, and the professionals often seem to work rather for the carers than directly for the patients. 
It seems also to be true that many close relations have been threatened or destroyed by too much candour.

\section{Acknowledgement of reciprocal obligations, fidelity and promise keeping}

Any social contract involves mutual rights and obligations. In therapy the contract concerns specifically the patient's health and should include the right to honest information about diagnosis and prognosis. However, it could be argued that many patients with dementia are not able to enter any social contract simply as a direct result of their cognitive impairment, and the primary obligation of their doctors remains the principle "not to harm". It has also been claimed that doctors, like everyone else, have a duty not to lie but are not duty-bound to avoid deception. ${ }^{24}$

ARGUMENTS FOR LIMITED TRUTH-TELLING OR LYING Arguments for limited disclosure and deception quoted by Beauchamp and Childress include the following.

\section{Therapeutic privilege}

Honesty should not be confused with cruel openness ${ }^{25}$ and if disclosure of the information seems to be harmful to the patient, it may be justified for the doctor to withhold the information or even to use benevolent deception. The therapeutic privilege has a long tradition in medical practice, although more recently it has been criticised as an example of unacceptable paternalism. Misleading the patient contributes to the cult of expertise surrounding the medical profession and to a view of doctors not as providing a service, but as guardians of a special wisdom, which they may determine when, and to whom, to divulge. ${ }^{26} \mathrm{How}-$ ever, paternalism frequently appears to be unavoidable in dementia care and some professionals still defend telling lies to cognitively impaired patients. ${ }^{27}$ After all anxiety, depression, catastrophic and psychotic reactions do happen as the result of disclosure ${ }^{28}$ and even suicides committed by patients unable to live with the burden have been reported. ${ }^{29}$

Patients are not able to understand the information This may be a convincing excuse in the case of dementia, when there are difficulties in acquiring any new information complicated by memory deficits, impairments in the use of language and the ability to understand abstract concepts. But it may be argued that just because of the nature of dementia, patients should know well in advance about the threats to their intellectual functioning. They experience their illness and deserve an explanation of what is happening to them. Moreover, cognitive deficits do not remove their right to know the truth - they only make it more difficult for the doctor to provide understandable information to the patient. Lying and deceiving seem to deny them due respect and degrade their dignity. As in any other group of disorders, the patients with dementia require affirmation because they are persons, not just because they have been examined and found rational and competent. The truth may be neither fully understood nor remembered by the patient and difficult for the doctor, but neither of these problems should remove the obligation to be honest and truthful.

Some patients do not want to know the truth about their condition

Besides the right to know, there is also the right not to know. Patients may prefer to ignore the truth completely or to select only those parts of it which they want to know. If we accept that doctors ought to respect their patients' wishes, then the important issue is not what family members, other patients or professionals think, but what the patient in the particular circumstances wants. ${ }^{30}$ In my study a significant proportion of the participants $(30 \%)$ preferred not to be informed about their illness and their motives seemed to be diverse. This requires careful attention from health care professionals who should not force unwanted information on patients but rather should seek to understand their patients' preferences and act according to their choices.

\section{Conclusions}

Veracity appears to be a difficult virtue and a difficult-to-fulfil obligation. It remains difficult to reconcile conflicting principles and to judge how much information a patient should be given. Additional ambiguities may arise because of the difficult, sometimes impossible, task of balancing autonomy and paternalism. The review of the literature reveals that in dementia it is also unclear if knowing the truth about one's own health is the right of the person, or a privilege available to those who are sufficiently bright to understand the information, brave enough to request it explicitly and strong enough to cope with its burden. My study seems to suggest that we really ought to ask patients with dementia whether they wish to know more about their diagnosis. Each patient must be approached individually and his choices respected whatever the level of his impairment. Furthermore, having discussed the diagnosis once, we may need to go over it again, which implies that we must have the requisite communication skills to 
provide information in various ways. However, the effect of telling or not telling dementia patients their diagnoses remains unknown and requires a further prospective study.

\section{Acknowledgments}

I would like to thank Professor K W M Fulford for his valuable comments and encouragement when preparing this paper for publication, and Dr D Battin for his inspiration and support for the study.

Marek Marzanski, MD, MRCPsych, is a Specialist Registrar in Old Age Psychiatry, currently employed as a Locum Consultant at Coventry Healthcare NHS Trust.

\section{References}

1 Rice K, Wagner N. Breaking the bad news: what do psychiatrists tell patients with dementia about their illness International fournal of Geriatric Psychiatry 1994;9:467-71.

2 Rice K, Warner N, Tye T, Bayer A. Geriatricians' and psychiatrists' practice differs. British Medical fournal 1997;314:376.

3 Maguire CP, Kirby M, Wen R, Coakley D, Lawlor BA, O'Neill D. Family members' attitudes towards telling the patient with Alzheimer's disease their diagnosis. British Medical fournal 1996;313:529-30

4 Barnes R C. Telling the diagnosis to patients with Alzheimer's disease: relatives should act as proxy for patient. British Medical disease: relatives should

5 Smith A, King E, Hindley N, Barneston L, Barton J, Jobst KA. The experience of research participation and the value of diag nosis in dementia: implications for practice. fournal of Mental Health 1998;7,3:309-21

6 Erde EL, Nadal EC, Scholl TO. On truth telling and the diagnosis of Alzheimer's disease. The fournal of Family Practice 1988;26:401-6.

7 World Health Organisation. The ICD-10 classification of mental and behavioural disorders: clinical descriptions and diagnostic guidelines. Geneva: World Health Organisation, 1992:45-56.

8 McKeith I, Galasko D, Kosaka K, Perry EK, Dickson D, Hansen LA, et al. Consensus guidelines for the clinical and pathologic diagnosis of dementia with Lewy bodies (DIB): report of the consortium on DLB international workshop. Neut rology $1996 ; 47: 1113-24$

9 Folstein M, Folstein SE, McHugh PB. Mini-mental state. A proin 1 , Folstein SE, Mct practical method for grading the cognitive state of patients for
10 Bahro M, Silber E, Sunderland T. How do patients with Alzheimer's disease cope with their illness? A clinical experience report. Fournal of the American Geriatrics Society 1995;93:291-6.

11 Kubler-Ross E. On death and dying. London: Tavistock, 1970

12 British Medical Association. Medical ethics today: its practice and philosophy. London: BMJ Publishing Group,1993:10:326-8.

13 Bloch S, Chodoff P, eds. Psychiatric ethics. Oxford: Oxford UniversityPress, 1993: 524-6.

14 General Medical Council. The duties of a doctor. Good medical practice. Guidelines to doctors. London: General Medical Council, 1995: 4.

15 Pitt B. You've got Alzheimer's disease: telling the patient. Current Opinion in Psychiatry 1997;10:307-8.

16 Fitts WT, Ravelin IS. What Philadelphia physicians tell patients with cancer. Fournal of the American Medical Association 1953;153:901-4.

17 Novack DM, Plumer R, Smith RL, Ochitill M, Morrow GR, Bennet JM. Change in physicians' attitude towards telling the cancer patient. Fournal of the American Medical Association 1979;241:897-900.

18 Meyers S. Telling patients they have Alzheimer's disease. British Medical fournal 1997;314:321-2.

19 Alzheimer Scotland. The right to know? Edinburgh: Action on Dementia, 1997.

20 Green RS, Gantt AB. Telling patients and families the psychiatric diagnosis: a survey of psychiatrists. Hospital and Community Psychiatry 1987;38:666-8

21 Beauchamp TC, Childress J F. Principles of biomedical ethics [4th ed]. Oxford: Oxford University Press, 1994:395-461.

22 Hope T. Deception and lying. Fournal of Medical Ethics 1995;21:67-8.

23 Agich SJ. Autonomy and long term care. Oxford: Oxford University Press, 1993.

24 Jackson J. Telling the truth. Fournal of Medical Ethics 1991;17:5-9.

25 Jackson J. On the morality of deception - does method matter? A reply to David Bakhurst. Fournal of Medical Ethics 1993;19:183-7.

26 Bakhurst D. On lying and deceiving. Fournal of Medical Ethics 1992;18:63-6.

27 Cutcliffe J, Milton J. In defence of telling lies to cognitively impaired elderly patients. International fournal of Geriatric Psychiatry 1996;11:1117-18.

28 Drickamer M, Lachs MS. Should patients with Alzheimer's disease be told their diagnosis? The New England fournal of Medicine 1992;326:947-51.

29 Rohde K, Peskind ER, Raskind MA. Suicide in two patients with Alzheimer's disease. Fournal of the American Geriatrics Society 1995;43:187-9.

30 Gillon R. Telling the truth and medical ethics. In: Gillon R. Philosophical medical ethics. Chichester: John Wiley \& Sons, 1986:100-5. 